\title{
Perceptions and behavior-related intentions of consumers in smartphone-based mobile commerce
}

\author{
Maria Gabriela Horga $^{1}$, Elvira $\mathrm{Nica}^{2, *}$, and Dumitru Nancu ${ }^{1}$ \\ ${ }^{1}$ Ovidius University, Department of Economics, Mamaia 124, 900527, Constanța, Romania \\ ${ }^{2}$ The Bucharest University of Economic Studies, Department of Economics, Piața Romană 6, 010374 , \\ Bucharest, Romania
}

\begin{abstract}
.
Research background: This article presents an empirical study carried out to evaluate and analyze perceptions and behavior-related intentions of consumers in smartphone-based mobile commerce globally.

Purpose of the article: Building our argument by drawing on data collected from Nielsen and Statista, we performed analyses and made estimates regarding positive and negative aspects of smartphone shopping according to EU mobile shoppers, mobile shopping activities among smartphone and tablet owners, mobile visits to leading retail websites in the U.S., and most popular payment methods for everyday transactions according to Internet users worldwide.

Methods: Data collected from 4,400 respondents are tested against the research model by using structural equation modeling.

Findings \& Value added: The sudden advancement of mobile technology has driven numerous retailers to strive and capitalize on smartphones as a supplementary tool in the operation of sales. Smartphone applications as an innovative channel can be carried out in retail marketing mix for the purpose of constituting constructive customer relationships. Consumer use of mobile shopping applications constitutes a thought-provoking difficult task for retailers and application developers. Habit and omnipresence unswervingly shape customers' purposes and concrete mobile shopping usage behaviors. The browsing extent and rate of recurrence of nonshopping applications clarifies the quantity of shopping software mobile users hold on their smartphones. Product reviews are paramount to users and a manner of gaining information unspecified by the retailer.
\end{abstract}

Keywords: perception; behavior; smartphone; mobile; commerce

JEL Classification: $E 24 ; J 21 ; J 54 ; J 64$

\footnotetext{
* Corresponding author: popescu elvira@yahoo.com
} 


\section{Introduction}

Smartphone applications as an innovative channel can be carried out in retail marketing mix for the purpose of constituting constructive customer relationships. Individuals' perception of implementation, output, and usefulness after employing applications is positively associated with their value perception. The latter and shopping through the applications channel may be utilitarian or hedonic [1] inherently being determined by the product consumption. User attitude, purpose and behavior in relation to smartphone applications retail channel may arise from their perception with respect to physical shop or kind of online store [2].

\section{Conceptual Framework and Literature Review}

Employment of mobile technologies to set up a feasible link between retailers and consumers has swiftly materialized as a decisive component [3] in demarcating efficient retailers from their less organized rivals. The control, setting, applicability, and subject matter of such information are paramount aspects in catalyzing the significant purchase experience that mobile users require from retailers. Consumers have quickly become more aware of their enablement, especially in the spheres of pricing, product choice, and user service. Helpful notifications, digital purchase lists, in-store guidance tools, personalized vouchers and promotions, and accommodating checkout operations constitute user service activities facilitated by the employment of mobile technologies that improve consumers' impression of enablement. Such empowerment furnished by mobile devices is thoroughly altering the customer-retailer cooperation from transaction-oriented to more value-led [4], consequently establishing feasible brand commitment for the retailer and providing the appropriate experience that mobile users expect [5].

Habit and omnipresence unswervingly shape customers' purposes and concrete mobile shopping usage behaviors. Well-designed predispositions and recurrent actions [6] regulate decision-making and behavior. Behavioral purpose is a relevant and positive predictor [7] of concrete mobile shopping usage. Technology readiness is a consumer's willingness to adopt mobile shopping. The impact of omnipresence on purpose to adopt mobile shopping is considerably superior for users being at a preliminary readiness stage. Habit is a notably more established predictor of purpose [8] to adopt actual mobile shopping usage for users being at a sophisticated readiness stage. The implication of habit and omnipresence on purpose and actual mobile shopping usage behavior is situation dependent. The more stable the habit, the less important the predictive capacity of omnipresence on purpose to adopt mobile shopping. The effectiveness of omnipresence in predicting usage purpose [9] is diminished by a significant degree of habit. Indecision prevention (ambiguity and risk) does not shape consumers' purposes and concrete mobile shopping [10].

\section{Methodology and Empirical Analysis}

This article presents an empirical study carried out to evaluate and analyze perceptions and behavior-related intentions of consumers in smartphone-based mobile commerce globally. Building our argument by drawing on data collected from Nielsen and Statista, we performed analyses and made estimates regarding positive and negative aspects of smartphone shopping according to EU mobile shoppers, mobile shopping activities among smartphone and tablet owners, mobile visits to leading retail websites in the U.S., and most popular payment methods for everyday transactions according to Internet users worldwide. Data collected from 4,400 respondents are tested against the research model by using 
structural equation modeling. Survey method: The interviews were conducted online and data were weighted by five variables (age, race/ethnicity, gender, education, and geographic region) so that each country's sample composition reliably and accurately reflects the demographic profile of the adult population according to the country's most recent census data. Sampling errors and test of statistical significance take into account the effect of weighting. Stratified sampling methods were used and weights were trimmed not to exceed 3. Average margins of error, at the $95 \%$ confidence level, are $+/-2 \%$. For tabulation purposes, percentage points are rounded to the nearest whole number. The precision of the online polls was measured using a Bayesian credibility interval. An Internet-based survey software program was utilized for the delivery and collection of responses.

\section{Results and Discussion}

Product reviews are paramount to users and a manner of gaining information unspecified by the retailer. Users rely on such comments over marketing and sales assistants' guidance. Users commonly employ their smartphones to balance effortlessly and swiftly the differences between products [11], getting a sense of security by being sure of identifying the best price, turning thus this in-store behavior into a natural component of their shopping routine. Smartphones are employed to assist users in their endeavors to identify the adequate product in-store. Consumers also use their smartphones to gain information instead of asking sales assistants or as a manner of verifying or challenging details [12] supplied to them by retailers and in marketing stuff. Smartphones offer a relevant advantage when aiming a discount purchase. Sometimes customers evaluate commodities in-store to be in no doubt they fit as intended and buy them online at a diminished price. Value shopping is a constitutive component of mobile purchase [13], as the retail outlet becomes a showroom, a setting for appraising products without buying them. Mobile purchase is therefore a convenient and an economical manner of shopping (Table 1) [14].

Table 1. Positive and negative aspects of smartphone shopping according to EU mobile shoppers (\%)

\begin{tabular}{|l|l|}
\hline I have no shopping problems from my mobile device & 69 \\
\hline I like that I can shop anywhere from my mobile phone & 66 \\
\hline I prefer to shop on my laptop/desktop computer & 51 \\
\hline I find it easier to shop on a desktop/laptop because of the keyboard and larger screen size & 49 \\
\hline I never make purchases online or from a retailer's app while in that store & 45 \\
\hline Sometimes I use a retailer's app on my phone to make purchases while I am in that store & 46 \\
\hline The larger keyboard and screen size on a desktop/laptop computer does not matter to me & 44 \\
\hline I prefer to shop on my mobile device & 43 \\
\hline It does not matter to me that I can use my mobile device here when shopping & 34 \\
\hline Shopping on my mobile device can be frustrating & 31 \\
\hline
\end{tabular}

Sources: Statista; our survey among 4,400 individuals conducted February 2020.

Consumer use of mobile shopping applications constitutes a thought-provoking difficult task for retailers and application developers. Smartphones have modified to a large extent the user practice in mobile shopping [15], making possible the setting up of an innovative channel which retailers may adopt to supply more customized products to their customers. Retailers are carrying out superior levels of investment in designing and reconsidering their online shopping offerings [16] via personalized mobile purchasing applications which are adjusted to the interface reminders of smartphones and enable characteristics that can improve user convenience. The risk perception among users is intrinsic in online transactions as a consequence of spatial and temporal disconnection [17] from the retailers and performs the function of a hindrance to the acceptance of new technologies. Concerns 
associated with breakdown, mobile networks limitation, and content problems pose critical security and privacy risks for users. Adopting mobile shopping applications necessitates elementary resources and skills (Table 2) [18].

Table 2. Most popular payment methods for everyday transactions according to Internet users worldwide (\%)

\begin{tabular}{|l|l|}
\hline In-store & 36 \\
\hline Other online & 19 \\
\hline Buy buttons & 13 \\
\hline Other mobile transfers & 11 \\
\hline P2P transfer & 11 \\
\hline Mobile messenger apps & 10 \\
\hline QR codes & 7 \\
\hline Other in-app payments & 5 \\
\hline Smart home device & 5 \\
\hline Wearables/Contactless & 3 \\
\hline Other & 1 \\
\hline
\end{tabular}

Sources: Statista; our survey among 4,400 individuals conducted February 2020.

With the swift expansion of smartphones, retailers supply innovative types of interactive communication mechanisms [19], facilitating to their users access via the mobile channel. Goods that have characteristics of experience products or credence commodities are likely to be acquired through mobile and Internet routes that offer complete and cumulative information (e.g. consumer reviews) (Table 3) [20].

Table 3. Mobile visits to leading retail websites in the U.S. (\%)

\begin{tabular}{|l|l|}
\hline Apple & 74 \\
\hline Amazon & 67 \\
\hline Macy's & 44 \\
\hline Home Depot & 43 \\
\hline Wayfair & 42 \\
\hline Target & 37 \\
\hline BestBuy & 36 \\
\hline Walmart & 34 \\
\hline Kohl's & 31 \\
\hline Lowe's & 29 \\
\hline
\end{tabular}

Sources: Statista; our survey among 4,400 individuals conducted February 2020.

The browsing extent and rate of recurrence of non-shopping applications clarifies the quantity of shopping software mobile users hold on their smartphones. Acquisitions made through purchasing applications are grasped by user digital practice [21] and the browsing data of shopping software. Digital practice is more sensitively related to the ownership of online retailer applications than of conventional ones. The constancy of non-shopping application usage is unrelated to ownership of online applications. Acquisitions made through online retailer applications are clarified by digital practice and browsing behavior of online applications. Mobile practice and browsing behavior [22] of conventional applications are most relevant for established retailers. While intense online browsing of non-shopping sites results in online purchasing, the validity of intense mobile browsing as a predictor of mobile buying relies on whether the consumers browse non-shopping or preloaded applications (Table 4) [23]. 
Table 4. Mobile shopping activities among smartphone and tablet owners (\%)

\begin{tabular}{|l|l|l|}
\hline & Smartphone & Tablet \\
\hline Using store locator to find store & 78 & 46 \\
\hline Checking price & 66 & 54 \\
\hline Research item before purchase & 58 & 67 \\
\hline Reading review of recent/future purchase & 48 & 62 \\
\hline Using lists while shopping & 45 & 23 \\
\hline Using mobile coupon & 38 & 18 \\
\hline Purchasing item on device & 32 & 43 \\
\hline Using device for payment & 31 & 31 \\
\hline Using social media to comment on purchase & 25 & 26 \\
\hline Writing a review of a purchase & 15 & 24 \\
\hline
\end{tabular}

Sources: Nielsen; our survey among 4,400 individuals conducted February 2020.

\section{Conclusions and Implications}

The sudden advancement of mobile technology [24] has driven numerous retailers to strive and capitalize on smartphones as a supplementary tool in the operation of sales. In respect of the use of the mobile payment system by Short Message Service, the most significant variables in order of relevance in the purpose to adopt are: the attitude, perceived practicality, subjective standards, and perceived security. With reference to the use of the Near Field Communication mobile payment system, the most significant variables in order of relevance in the purpose to adopt are: the attitude, subjective standards, perceived practicality and perceived security [25].

All authors listed have made a substantial, direct and intellectual contribution to the work, and approved it for publication.

The authors declare that the research was conducted in the absence of any commercial or financial relationships that could be construed as a potential conflict of interest.

\section{References}

1. Mircică, N. (2019). Cyber-physical systems for cognitive industrial Internet of Things: sensory big data, smart mobile devices, and automated manufacturing processes. Analysis and Metaphysics, 18, 37-43.

2. Rezaei, S., Valaei, N. (2017). Crafting experiential value via smartphone apps channel. Marketing Intelligence \& Planning, 35(5), 688-702.

3. Adams, C., Grecu, I., Grecu, G., Balica, R. (2020). Technology-related behaviors and attitudes: Compulsive smartphone usage, stress, and social anxiety. Review of Contemporary Philosophy, 19, 71-77.

4. Gray-Hawkins, M., Michalkova, L., Suler, P., Zhuravleva, N. A. (2019). Real-time process monitoring in Industry 4.0 manufacturing systems: Sensing, smart, and sustainable technologies. Economics, Management, and Financial Markets, 14(4), 30 36.

5. Faulds, D. J., Mangold, W. G., Raju, P. S., Valsalan, S. (2018). The mobile shopping revolution: Redefining the consumer decision process. Business Horizons, 61(2), $323-$ 338.

6. Mihăilă, R. (2018). The ascendance of postmodernism in the educational sphere. Educational Philosophy and Theory, 50(14), 1578-1579. 
7. Pickard, M., Grecu, I., Grecu, G. (2019). Sustainable smart manufacturing in Industry 4.0: Real-time resource planning, process monitoring, and production control. Economics, Management, and Financial Markets, 14(3), 30-36.

8. Tooby, C. (2019). Governance mechanisms of analytical algorithms: The inherent regulatory capacity of data-driven automated decision-making. Contemporary Readings in Law and Social Justice, 11(1), 39-44.

9. Westbrook, L., Pera, A., Neguriță, O., Grecu, I., Grecu, G. (2019). Real-time datadriven technologies: Transparency and fairness of automated decision-making process governed by intricate algorithms. Contemporary Readings in Law and Social Justice, 11(1), 45-50.

10. Ashraf, A. R., Thongpapanl, N., Menguc, B., Northey, G. (2017). The role of MCommerce readiness in emerging and developed markets. Journal of International Marketing, 25(2), 25-51.

11. Sion, G. (2019). Self-portraits in social media: Means of communicating emotion through visual content-sharing applications. Linguistic and Philosophical Investigations, 18, 133-139.

12. Kassick, D. (2019). Workforce analytics and human resource metrics: Algorithmically managed workers, tracking and surveillance technologies, and wearable biological measuring devices. Psychosociological Issues in Human Resource Management, 7(2), 55-60.

13. Durkin, K. (2019). Artificial intelligence-driven smart healthcare services, wearable medical devices, and body sensor networks. American Journal of Medical Research, 6(2), 37-42.

14. Fuentes, C., Svingstedt, A. (2017). Mobile phones and the practice of shopping: A study of how young adults use smartphones to shop. Journal of Retailing and Consumer Services, 38, 137-146.

15. Meyers, T. D., Vagner, L., Janoskova, K., Grecu, I., Grecu, G. (2019). Big data-driven algorithmic decision-making in selecting and managing employees: Advanced predictive analytics, workforce metrics, and digital innovations for enhancing organizational human capital. Psychosociological Issues in Human Resource Management, 7(2), 49-54.

16. Sion, G. (2019). Commodifying intimate relationships through geosocial networking mobile apps: Data-driven dating, sexual sociality, and online body objectification. Journal of Research in Gender Studies, 9(2), 78-84.

17. Lăzăroiu, G. (2018). Postmodernism as an epistemological phenomenon. Educational Philosophy and Theory, 50(14), 1389-1390.

18. Chopdar, P. K., Korfiatis, N., Sivakumar, V. J., Lytras, M. D. (2018). Mobile shopping apps adoption and perceived risks: A cross-country perspective utilizing the Unified Theory of Acceptance and Use of Technology. Computers in Human Behavior, 86, 109-128.

19. Krech, S. (2019). Medical big data analytics and smart Internet of Things-enabled mobile-based health monitoring systems. American Journal of Medical Research, 6(2), 31-36. 
20. Park, S., Lee, D. (2017). An empirical study on consumer online shopping channel choice behavior in omni-channel environment. Telematics and Informatics, 34(8), 1398-1407.

21. Cadge, K., Lăzăroiu, G., Durana, P., Kovalova, E. (2019). Initiating sexual behaviors with online dating partners: Stereotypical gender norms, intimate personal data, and romantic compatibility. Journal of Research in Gender Studies, 9(2), 71-77.

22. Gutberlet, T. (2019). Data-driven smart sustainable cities: Highly networked urban environments and automated algorithmic decision-making processes. Geopolitics, History, and International Relations, 11(2), 55-61.

23. Kim, M., Kim, J., Choi, J., Trivedi, M. (2017). Mobile shopping through applications: Understanding application possession and mobile purchase. Journal of Interactive Marketing, 39, 55-68.

24. Lyakina, M., Sheehy, M., Podhorska, I. (2019). Networked and integrated urban technologies in Internet of Things-enabled smart sustainable cities. Geopolitics, History, and International Relations, 11(2), 62-68.

25. Liébana-Cabanillas, F., de Luna, I.R., Montoro-Ríos, F. (2017). Intention to use new mobile payment systems: a comparative analysis of SMS and NFC payments. Economic Research-Ekonomska Istraživanja, 30(1), 892-910. 